\title{
Analysis of heat transfer enhancement in Rectangular microchannel using refrigerant- $\mathrm{R} 22$
}

\author{
Rohit Pingale*, Shriramshastri Chavali and Vivekanand Navadagi \\ Dhole patil College of Engg., Pune University, Pune, India
}

Accepted 15 June 2016, Available online 20 June 2016, Special Issue-5 (June 2016)

\begin{abstract}
Micro heat exchangers are becoming an important area of interest in many fields of developing technology that require compact high heat energy removal solutions. In our work numerical analysis is has carried out for rectangular micro channels with five sets of rectangular configurations, in order to find optimum configuration of microchannel. Analysis of rectangular microchannel has carried out for forced convection heat transfer condition with constant base area of $30 \mathrm{~mm}$ length and $20 \mathrm{~mm}$ width. Experimental test setup is in developing stage. As compare to other configurations the heat transfer coefficient is more and dominant so $260 \mu \mathrm{m}$ diameter microchannel diameter is more optimistic as compare to other configuration of microchannel theoretically. Also as the heat input increase the configuration with higher hydraulic diameter show less pressure drop as compare to hydraulic diameter of $260 \mu \mathrm{m}$.
\end{abstract}

Key Words: Microchannel, Heat transfer, Pressure drop, Heat transfer coefficient.

\section{Introduction}

In the comparison with conventional heat exchanger micro channel has a higher heat transfer performance low to moderate pressure drops, smaller geometric size and lower coolant requirement and lower operational cost.

Micro heat exchangers are very vital field in many developing areas that requires compact and high heat removal solutions. Areas such as macro electronic devices, aerospace applications are having space limitations so we have to search smaller heat exchanger which having high heat removal capacity. In last researches many discussion was done on validity of macro scale fluid flow relations with micro scale fluid flow relations. In today's word many applications required very high heat transfer devices maintaining their temperature below its operating temperature which affects its performance such that in case of high performance computers chips its temperature must be maintained below $100 \mathrm{c}$.

Experiment using R-22 and $\mathrm{CO} 2$ in a horizontal manifold feeding 21 parallel heat exchanger tube using counter flow water jacket as a heat source. Micro channel used in micro heat pump for microprocessor cooling or portable cooling devices, small scale stationary auxiliary power unit and cryosurgical probe for ablating tumors or treating heart arrhythmia. The applications of micro system are increasing day by day. Micro fluidic systems have many applications such as

*Corresponding author: Rohit Pingale micro-flow pumps, heat exchanger, valves, thin film coating, combustion, micro-flow sensors and biomedical and biochemical analysis instruments

\section{Literature Review}

Literature review has carried out for work carried out for microchannel with refrigerant and water as a medium. The literature review combines the experimental, theoretical and CFD analysis of microchannel as follows.

A.Vardhan and W.E.Dunn et al studied the heat transfer and pressure drop characteristics of R-22 in microchannel tubes air conditioning and refrigeration center' in which they studied about heat transfer and pressure drop characteristics for single-phase and two phase flow of refrigerants in micro channel tubes was conducted. The refrigerants tested were R-22, R-134a and R-407C. In addition to circular port tubes, squareport tubes were tested with R-22 for both single-phase and two-phase flow.

T. Kulkarni, C. W. Bullard, and K. Cho et alanalysed refrigerant side tradeoffs in microchannel evaporators' in which they studied that microchannel condensers have dominated the automotive a/c market by maximizing performance for a fixed size and weight, but must operate as evaporators if they are to be used in heat pumps.

SureshV, And Garimella Dong Liu et al studied about the microchannels considered ranged in width from 194 micrometer to 534 micrometer, with the 
channel depth being nominally five times the width in each case. Their study was conducted for water flowing under laminar conditions through microchannels machined in silicon water. Heat fluxes as high as $790 \mathrm{~W} / \mathrm{cm}^{2}$ were achieved with the chip temperature maintained below 110 degree Celsius.

Honggi Cho and Keumnam Cho et al studied the Performance of microchannel evaporators with refrigerant R-22, in which they do an experimental study on the performance comparison of microchannel evaporators with refrigerant R-22 was conducted. The experiment was performed with both vapor compression system and refrigerant circulation system. The cooling capacity proportionally increased as the vertical inclination angle of the evaporator increased due to gravity force.

P.Kendra, And Ronald J,Juan et al studies on Liquid Flows in Microchannels, in which they studied about the Nominally, microchannels can be defined as channels whose dimensions are less than 1 millimeter and greater than 1 micron. Above 1 millimeter the flow exhibits behavior that is the same as most macroscopic flows.

Mirza Mohammed Shah, And Etcher Thompson et a lstudied heat transfer during condensation inside small channels. In which he studied about Prediction of heat transfer during film condensation in mini and microchannels is of much practical interest. No wellverified method for this purpose is available. The applicability of the author's well-validated general correlation for condensation in tubes to small channels is investigated in this paper.

P.Gunasegara,H,A. Mohammed, N.H. Shuaib, R.Saidur et alstudied about the effect of geometrical parameters on heat transfer characteristics of microchannel sheet sink with different shapes and give summary about their study as follow, they carried out work on geometrical parameters on heat transfer characteristics of microchannel sheet sink with different shapes. Poiseuille number increases evidently when $\mathrm{H} / \mathrm{a}$ and $\mathrm{L} / \mathrm{Dh}$ decreases while b/a increases The tip angle of triangular shaped micro channels has a great effect on the Poiseuille number. Poiseuille number increases evidently with the increase of tip angle from $\beta=22.14^{\circ}-51.95^{\circ}$.

Saptarshi Basu, Sidy Ndao, Gregory Michna, Yoav Peles , Michal k. Jensen et alstudied the Flow boiling of R134a in circular micro tubes for critical heat flux condition and fended the experimental critical heat flux data and plot the different graphs on it for the internal diameter of $0.50 \mathrm{~mm}, 0.90 \mathrm{~mm}$, and $1.60 \mathrm{~mm}$.(CHF)Critical heat flux. The Thomsen map identified the flow regime as annular in all three test section.

B.S.Gawali et al carried out analysis of rectangular microchannel for water as cooling medium. CFD analysis of rectangular microchannel carried out to analyse flow assumptions in microchannel. Based on experimental results a non dimensional co relation is proposed for rectangular microchannel.

Dingkunli et al studied Copper microchannel for HVAC, in which he studied about Micro-channel heat exchangers are the latest trend in for heating and cooling technologies providing up to a $40 \%$ increase in efficiency. Most micro-channel heat exchangers on the market today are constructed out of aluminum. The invention is a method to produce a copper microchannels tube.

P.Kendra, And V. V.Dharaiya and S. G. Kandlikar et.al.studied about the Numerical investigation of heat transfer in rectangular microchannel under $\mathrm{H} 2$ boundary conditioning during fully develop laminar flow for five different cases In present work rectangular microchannel with aspect ratio from 0.1 to 10 are numerically simulate by using CFD software.

Chad D. Bowers, Helena Mai, Stefen Elbel, Pega Hrnjak et al studied the refrigerant distribution effect on the performance of microchannel evaporator. They studied the flow pattern in various directions evaporator coil orientation by experimental study by flowing the refrigerant over the coils.Pressure drop for the refrigerant R245fa was almost three times higher than that of R134a for the same operating condition.

V.Alagesan et al studied flow boiling heat transfer in mini and micro channels. In which he studied about a comprehensive review of flow boiling heat transfer characteristics of various working fluids in mini and micro channels is presented in this paper. Due to their high heat transfer and heat removal properties, two phase flows have been studied and applied into the electronics cooling systems. Further developments in existing research for future research based on this area of review have been established.

Laith Jaafer Habeeb ,Riyadh S. and Al-Turaihi et alstudied the experimental study and CFD simulation of two phase flow around triangular obstacle in enlarging channels for the study of theoretical analysis and experimental highlighting bubbly flow around the triangular bodies in horizontal bodies.

Zhannu Zhou, and Xiande Fang et al studied Evaluation of Correlations of flow boiling heat transfer of R-22 in horizontal channels' in which the studied about the calculation of two phase flow boiling heat transfer of R22 in channels is required in a variety of applications, such as chemical process cooling systems, refrigeration, and air conditioning. Two correlations for R-22 with the mean absolute deviation $32.7 \%$ and $32.8 \%$ analysed.

A. Nomerotski, J. Buytart, P. Colline, R. Dumps, E. Greening, M. John, A. Mapelli, A. Leflat, Y. Li., G Romagnoli and B. Verlaathas studded the experimental and graphical analysis of Evaporative CO2 cooling using microchannels etched in silicon for the future LHCb vertex detector. They have prepared the microchannels on silicon by using the etching process on the chip (plate) for the experimental analysis.

Tom Saenen and Martine Baelman et al studied about the size effect of portable two-phase electronic cooling system they studied the results from numerical system model are discuses for analytical model. A parameter study performed on small size of cooling system it shows that increasing in boiling temperature a decrease in vapor quality or mass flow rate. 
P. Rosa , T. G. Karayiannis and M. W. Collins [20] has studied the single phase heat transfer in microchannel the importance of scaling effect for study the enhance effect, temperature properties. Mathematical macroscopic and microscopic models for sub continuum effect in flied flows have been review and explained.

\subsection{Objective Preferred}

These measurements tend to be invasive and limit the ability to study how refrigerant distribution in heat exchangers affects both heat exchanger and system performance. Heat transfer coefficients increase with exit pressure at the same exit quality for moderate and high mass fluxes. This is in agreement with findings in the literature for conventional and mini channels. For the most part, heat transfer coefficients displayed similar qualitative trends at reduced and atmospheric pressures. Depending on the mass flux and heat flux, both nucleate and convective dominant boiling mechanisms have been detected. A transition between nucleate and convective boiling was quantified. For sub atmospheric pressure data, nucleate boiling is dominant for low Re and Bo similar to atmospheric pressure data. However, the transition from the nucleate to convective dominant boiling heat transfer mechanism occurs at a lower $\mathrm{Re}$ and Bo than at atmospheric pressure.

\section{Numerical study of rectangular microchannels}

\subsection{Dimensions of microchannels consider for analysis}

Different height, widths are considered for analysis has listed in following table. Spacing for five test of microchannels are considered constant. Details of microchannel height, width, spacing, surface area and volume area are listed in table as follows.

Table 3.1 Dimension of rectangular microchannel

\begin{tabular}{|c|c|c|c|c|}
\hline Set-I & $\mathrm{a}-\mu \mathrm{m}$ & $\mathrm{b}-\mu \mathrm{m}$ & $\mathrm{s}-\mu \mathrm{m}$ & $\mathrm{N}$ \\
\hline 1 & 200 & 400 & 500 & 23 \\
\hline 2 & 300 & 400 & 500 & 23 \\
\hline 3 & 200 & 250 & 500 & 27 \\
\hline 4 & 300 & 350 & 500 & 24 \\
\hline 5 & 300 & 400 & 300 & 29 \\
\hline
\end{tabular}

Theoretical analysis can be done by theoretical calculations using various formulae and assumptions. We have used these formulae in for theoretical calculations and formulated tables and graphs using these calculations. Further various conclusions can be drawn using these results.

The assumptions for analysis are as follows

1] Flow is laminar

2] Refrigerant used is R22 and flow through the cycle is single phase only.
3] Heat supplied is constant from heater input at base surface area of microchannel.

4] Heat conduction and convection in microchannel is considered.

5] Heat loss to surrounding is assumed is negligible. While calculations we had considered following terms for analysis as follows,

In calculations following terms are considered for analysis of microchannels :

Heat input to microchannel is varied from 25 to $150 \mathrm{~W}$. Flow rate considered during analysis is 1 to $6 \mathrm{lit} / \mathrm{min}$. Length of microchannel is $30 \mathrm{~mm}$.

\subsection{Heat input (Q) Vs heat transfer coefficient (h)}

Heat input Vs heat transfer coefficient for different flow rate are analyzed with five sets of hydraulic diameters are shown in Fig. 3.1 to Fig 3.2. As the heat input increases there is increase in heat transfer coefficients. The graph shows horizontal characteristics. In nature for the different flow rate the heat transfer coefficient increases with increase in diameter as shown in figure 3.1 to figure 3.2. For flow rate of $0.0166 \mathrm{~kg} / \mathrm{sec}$ the microchannel with hydraulic diameter of $260 \mu \mathrm{m}$ the heat transfer coefficient is maximum of $10000 \mathrm{~W} \backslash \mathrm{m}^{2} \mathrm{~K}$ and for $330 \mu \mathrm{m}$ it is minimum of $2000 \mathrm{~W} \backslash \mathrm{m}^{2} \mathrm{~K}$.

Similarly for flow rate of $0.033 \mathrm{~kg} / \mathrm{sec}$ for hydraulic diameter of $260 \mu \mathrm{m}$ heat transfer coefficient is 10000 $\mathrm{W} \backslash \mathrm{m}^{2} \mathrm{~K}$ and for $330 \mu \mathrm{m}$ it is observed is about of 2200 $\mathrm{W} \backslash \mathrm{m}^{2} \mathrm{~K}$. For flow rate of $0.06 \mathrm{~kg} / \mathrm{sec}$ and $0.1 \mathrm{~kg} / \mathrm{sec}$ the as the flow rate increased the with heat input the heat transfer coefficient is increases. But for higher hydraulic diameter the heat transfer coefficient is increases with increase in flow rate. For lower hydraulic diameter the heat transfer coefficient is maximum as shown in figure 3.1 to figure 3.2. It is seen that for different flow rate for hydraulic diameter of $260 \mu \mathrm{m}$ heat transfer coefficient is maximum and for rest of hydraulic diameters the heat transfer coefficient is in range of $14000 \mathrm{~W} / \mathrm{m}^{2} \mathrm{~K}$ to $2000 \mathrm{~W} / \mathrm{m}^{2} \mathrm{~K}$.

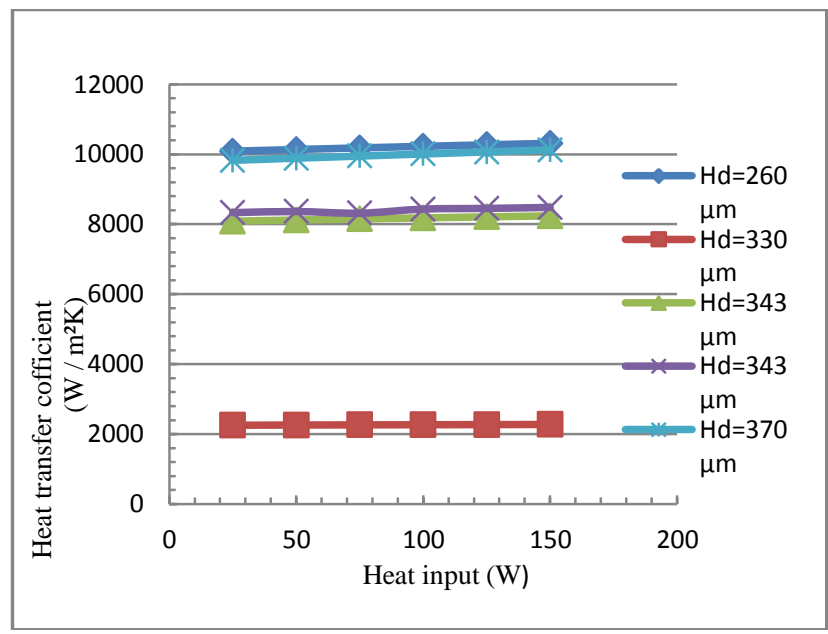

Figure 3.1 Heat input Vs heat transfer coefficient for flow rate of $0.0016 \mathrm{~kg} / \mathrm{sec}$ 


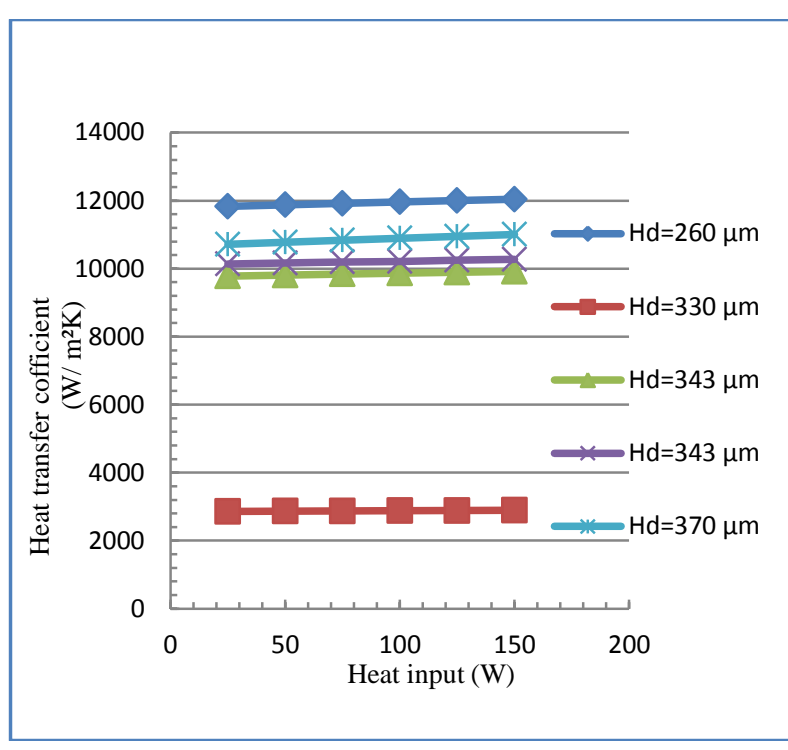

Figure 3.2 Heat input Vs heat transfer coefficient for flow rate of $0.033 \mathrm{~kg} / \mathrm{sec}$.

\subsection{Heat input Vs temperature difference}

Different graphs of figure 3.3 to figure 3.4.As the heat input increases the difference in temperature also increases. The graph shows linear characteristics. We have obtained graphs for different flow rate of 1 to 6 lit/min.With increase in hydraulic diameter temperature difference increases are shown in figure 3.3 to figure 3.4. The graph temperature difference $(\Delta T)$ Vs heat input $(Q)$ for various hydraulic diameters is shown. The flow rate here is $1 \mathrm{lpm}$.

It has been observed that for hydraulic diameter $0.000370 \mathrm{~m}$ the temperature difference is maximum i.e. $80{ }^{\circ} \mathrm{C}$ for 100 Watts while for heat input 20 Watts $\Delta \mathrm{T}$ is $16^{\circ} \mathrm{C}$.For hydraulic diameter of $343 \mu \mathrm{m} \Delta \mathrm{T}$ is $70^{\circ} \mathrm{C}$ for 100 Watt and $15{ }^{\circ} \mathrm{C}$ for 20 Watt. While for hydraulic diameter of $260 \mu \mathrm{m} \Delta \mathrm{T}$ is $60^{\circ} \mathrm{C}$ for $100 \mathrm{Watt}$ and $12^{\circ} \mathrm{C}$ for 20 Watt. $\Delta \mathrm{T}$ is minimum for hydraulic diameter $260 \mu \mathrm{m}$ i.e. $12^{\circ} \mathrm{C}$ at 20 Watts and $58^{\circ} \mathrm{C}$ at 100 Watts. From graph it has been seen that for all hydraulic diameters Temperature Difference varies linearly with respect to heat input. The graph $(\Delta \mathrm{T}) \mathrm{Vs}$. (Q) for flow rate $2 \mathrm{lit} / \mathrm{min}$ and various hydraulic diameters is shown. It has been observed that for hydraulic diameter $343 \mu \mathrm{m}$ the $\Delta \mathrm{T}$ is maximum i.e. $80{ }^{\circ} \mathrm{C}$ for 100 $\mathrm{W}$ heat input while $\Delta \mathrm{T}$ is minimum for hydraulic diameter of $260 \mu \mathrm{m}$ at $20 \mathrm{~W}$. From graph it has been seen that for all hydraulic diameters $\Delta \mathrm{T}$ varies linearly with respect to heat input.

The graph $(\Delta \mathrm{T})$ Vs. $(\mathrm{Q})$ for flow rate $6 \mathrm{lit} / \mathrm{min}$ and various hydraulic diameters is shown. It has been observed that for hydraulic diameter $343 \mu \mathrm{m}$ the $\Delta \mathrm{Ti}$ maximum $71^{\circ} \mathrm{C}$ for 100 Watts heat input while $\Delta \mathrm{T}$ is minimum for hydraulic diameter of $260 \mu \mathrm{m}$ at 20 Watt. From graph it has been seen that for all hydraulic diameters $\Delta \mathrm{T}$ varies linearly with respect to Heat Input.

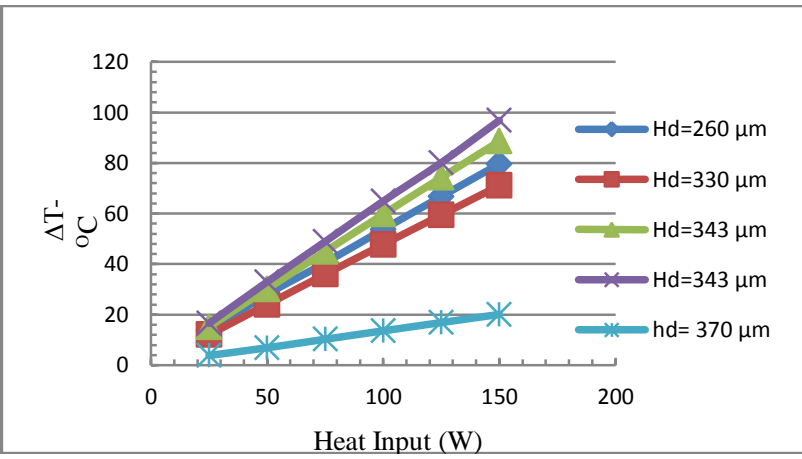

Figure 3.3 Temp difference Vs heat input for flow rate of $0.016 \mathrm{~kg} / \mathrm{sec}$

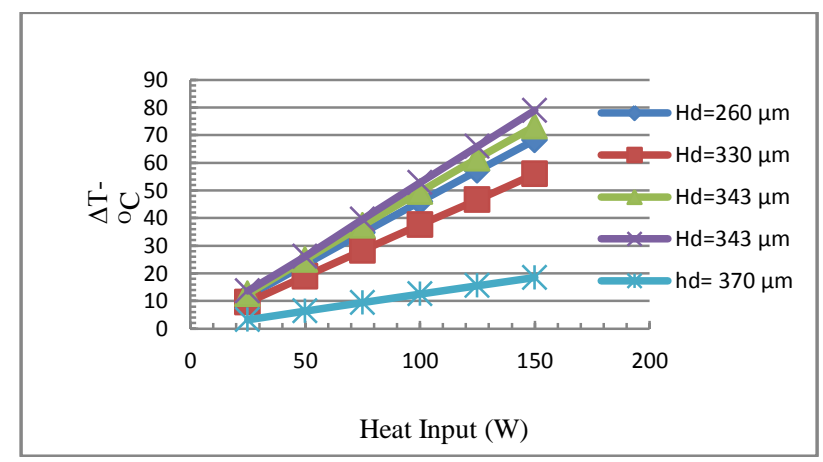

Figure 3.4 Temp difference Vs heat input for flow rate of $0.033 \mathrm{~kg} / \mathrm{sec}$

\section{Experimental analysis}

\subsection{Experimental Test Set Up}

Set up consist of compressor from which cooling refrigerant is circulated. Compressor is used for compressing the refrigerant up to sufficient high pressure and temperature as compression is done on vapor. After there is a condenser, where it is cooled at constant pressure by rejecting heat to condenser. The liquid from condenser goes to expansion valve where temp. And pressure reduces and converts into vapor. Finally low pressure, low temp, Refrigerant passes to manifold where it absorbs latent heat at constant pressure and convert into vapor state.Again supplied to the compressor. Thus cycle is completed .Accumulator act storing energy. It stores energy and when required by compressor. Heater is used for heating purpose in manifold. Rotameter is there for flow measurement. Piping is for circulation of cooling refrigerant. Manifold having inlet and outlet and have copper microchannel in it.

1] Set up consist of compressor from which cooling refrigerant is circulated.

2] Compressor is used for compressing the refrigerant up to sufficient high pressure and temperature as compression is done on vapor.

3] After there is condenser where it is cooled at constant pressure by rejecting heat to condenser.

4] The liquid from condenser goes to expansion valve where temp. And pressure reduces and converts into vapor. 
5] Finally low pressure, low temp. Passes to manifold where it absorbs latent heat at constant pressure and convert into vapor state.

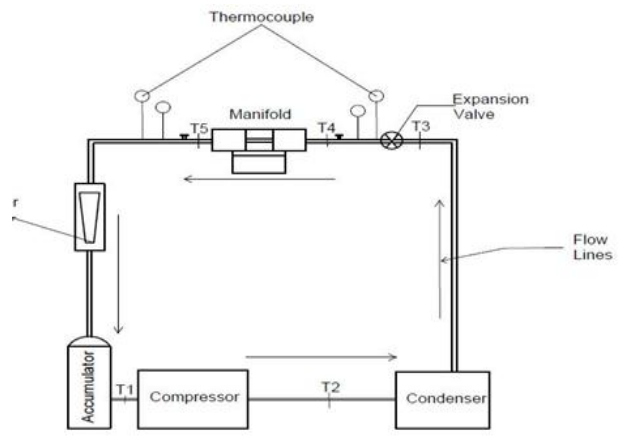

Figure 4.1 Flow loop of experimental test set up

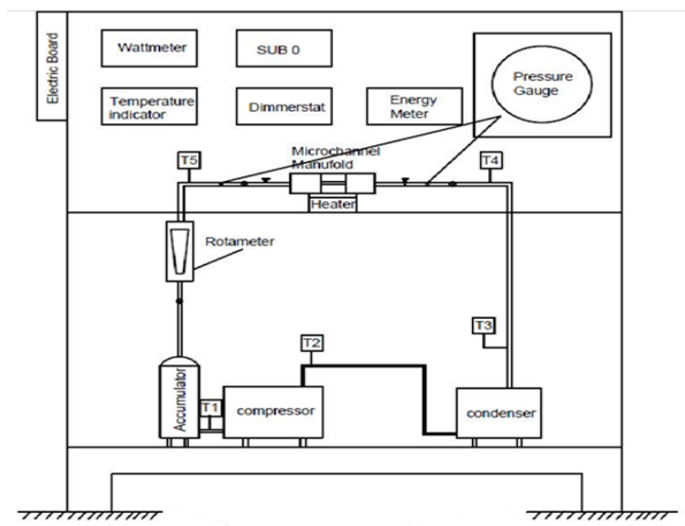

Figure 4.2 Test loop sysetm of microchannel

6] Again supplied to compressor. thus cycle is completed

7] Accumulator act storing energy. It stores energy and when required by compressor.

8] Heater is used for heating purpose in manifold.

9] Rotameter is there for flow measurement.

10] Piping for circulation of cooling refrigerant.

11] Manifold having inlet and outlet and have copper microchannel in it.

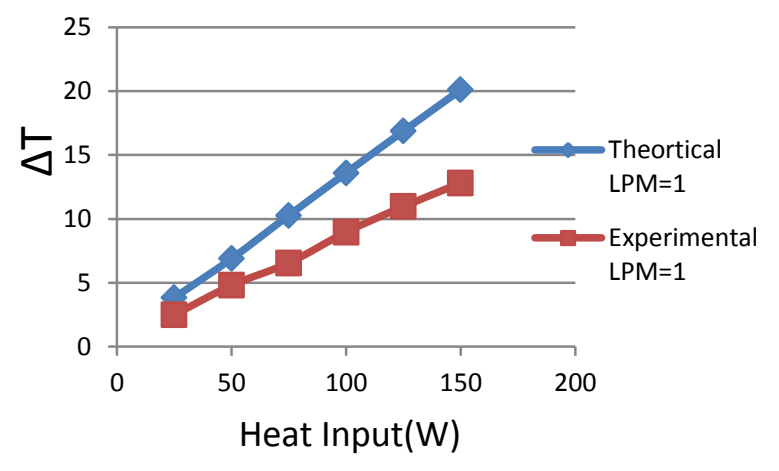

Fig.5.1 Heat input Vs temperature difference for flow rate of $0.016 \mathrm{~kg} / \mathrm{sec}$

\section{Conclusions}

Analysis is has carried out for rectangular micro channels of various configurations, in order to find optimum configuration of microchannel. Following are the overall conclusion.

1] The heat transfer coefficient for hydraulic diameter of $260 \mu \mathrm{m}$ is having value of $12000 \mathrm{~W} / \mathrm{m} 2 \mathrm{~K}$. As compare to other configurations the heat transfer coefficient is more so $260 \mu \mathrm{m}$ diameter microchannel diameter is more optimistic as compare to other configuration of microchannel theoretically.

2] As heat input increase the configuration with higher hydraulic diameter show less pressure drop as compare to hydraulic diameter of $260 \mu \mathrm{m}$. The range of pressure drop for microchannel is observed of 0.026 Kpa. For hydraulic diameter of $370 \mu \mathrm{m}$ the pressure drop is minimum of $0.01 \mathrm{Kpa}$

3] Experimental set up is developed and experimentation is in process. Numerical results will verified with experimental results.

\section{References}

A.Vardhan andW.E.Dunn 'heat transfer and pressure drop characteristics of $\mathrm{r}$ 22 in microchannel tubes air conditioning and refrigeration center'.in Year November 1997

T. Kulkarni, C. W. Bullard, and K. Cho refrigerant-side tradeoffs in microchannel evaporators'in year 2002

SureshV, And Garimella,Dong Liu Investigation of heat transfer in rectangula microchannels', published on 29 March 2004.

Honggi Cho and KeumnamCho'performance of microchannel evaporators with refrigerant R-22'in Year August 8,2007

P.Kendra, And Ronald JJuan'liquid flows in microchannels'in year 2008

Mirza Mohammed Shah and EtcherThompson 'heat transfer during condensation inside small channels.'published on 2010

P.Gunasegara,H,A.Mohammed,N.H.Shuaib,R.Saidur 'The effect of geometrical parameters on heat transfer characteristics of microchannel sheet sink with different shapes'in Year 2010.

Saptarshi Basu, SidyNdao, Gregory Michna, YoavPeles, Michal k. Jensen, Flow boiling of R134a in circular micro tubes for critical heat flux condition Journal of heat transfer, volume 133, 1-8, 2011

B.S.Gawali et al, Analysis of Rectangular Microchannel under Forced convection Heat Transfer condition, International Journal of Engineering Science and Technology (IJEST), Vol. 3 No. 3, 2041-2043, 2011.

B.S.Gawali et al Effect of Hydraulic Diameter on Rectangular Microchanne Under Single Phase Forced Convection Heat Transfer condition, International Journal of Mechanical Engineering, Volume-1 , Issue 2, Page Number 85-88, 2011.

Dingkunli Coppermicro channel for HVAC applications published on 201

V. V.Dharaiya and S. G. KandlikarNumerical investigation of heat transfer in rectangular microchannel under $\mathrm{H} 2$ boundary conditioning Journal of heat transfer, volume 134, page no 1-9 Feb 201

Chad D. Bowers , Helena Mai, StefenElbel, PegaHrnjakRefrigerant distribution effect on the performance of microchannel evaporator International conference refrigeration and air conditioning, Purdue. Vol 2173, page no 1 conferen

V.Alagesan Flow boiling heat transfer in mini and microchannels'published on 2012.

Laith JaaferHabeeb ,Riyadh S. and Al-Turaihi Experimental study and CFD simulation of two phase flow around triangular obstacle in enlarging channels, vol. 3, IACHE, 2036-2042, Jul-Aug 2013.

Zhannu Zhou, andXiande Fang 'Evaluation of Correlations of flow boiling heat transfer of R-22 in horizontal channels' on July 17,201

A. Nomerotski, J. Buytart, P. Colline, R. Dumps, E. Greening, M. John, A. Mapell A. Leflat, Y. Li., G. Romagnoli and B. Verlaat., Analysis of Evaporative $\mathrm{CO} 2$ cooling using microchannels etched in silicon for the future LHCb vertex detector, 2013

B.S.Gawali et al, Optimization of Rectangular Microchannel depth under forced convection Heat Transfer condition, International Journal of Review in Mechanical Engineering Research special issue of Heat Transfer, Praise Worthy Prize Publication, Volume - 7, No-2, 2013.

Tom Saenen and Martine Baelmans Size effect of portable two-phase electronic cooling system Celestijnenlaan 300A B-3001 Heverlee, Belgium.page no.127.2013.

P. Rosa, T. G. Karayiannis and M. W. Collins Single phase heat transfer in microchannel the importance of scaling effect for study the enhance effect Italy conference 2014

ModiShethFluid mechanics by DhanpatRai and sons publication New Delhi

R. S, Khurmi andGupta Refrigeration and Air Conditioning book by Tata McGraw Hill. 